\author{
Katarzyna Woźniak \\ Research and Innovation Centre Pro-Akademia \\ ul. Innowacyjna 9/11, 95-050 Konstantynów Łódzki, Poland, katarzyna.wozniak@proakademia.eu \\ (D) https://orcid.org/0000-0002-9871-732X
}

\title{
INFLUENCE OF OSH MANAGEMENT SYSTEM ON THE QUALITY AND SAFETY OF WORK
}

\begin{abstract}
The concept of occupational health and safety is not defined in Polish law. The only place where such a definition can be found is PN-N-1801:2004. Nevertheless, according to the Act on standardisation, the application of Polish Standards is voluntary. Activities in the field of occupational health and safety should be an integral part of business management. Companies from countries which are members of the European Union, in accordance with Directive 89/391/EEC, are obliged to implement standards related to occupational health and safety. The most commonly used and recognised standard for occupational health and safety management systems, in line with the specifics of each company, is the OHSAS 18001 international management system, while in Poland it is the PN-N-18001 standard. The study examined the scope of OHS at work among Research and Innovation Centre Pro-Akademia employees. The employees were subjected to surveys. The results obtained show that employees appreciate the importance of OHS regulations, but they do not always consciously comply with them. One of the tools that enabled author to prepare this article is analytic method called desk research. Desk Research is a research method that boils down to analyzing the records of available data sources, including in particular their compilation, mutual verification and processing. Such analysis is the basis for drawing conclusions about the examined problem. For example - the effect of the Desk Research analysis proceeded as part of the labor market survey is the diagnosis of the state of the labor market in the studied area, the characteristics of all its component groups as well as a description and verification of the actions taken by the institutions operating within it.
\end{abstract}

\section{Keywords}

management system, organisational culture, occupational health and safety, risk assessment, risk management, procedures

\section{Nomenclature, Abbreviations}

- OHS - Occupational Health and Safety

- OHS management system - part of the overall company management system

- Organizational structure - the arrangement of positions and the organisational units consisting of them (departments or other separate units) inside the organisation and the relationships between them (information flows, formal division of responsibilities, affiliations, etc.)

- Procedures - in other words: a way of conducting (type of activity);

- Processes - in organisation and management, it is most often defined as a set of activities, interrelated with each other, the implementation of which is necessary to obtain a specific result

\section{Introduction}

An indispensable element of managing the occupational health and safety (OSH) management system in a company is the need for extensive documentation. The bureaucracy associated with the proper performance of OHS obligations causes many problems for both business owners, managers and employees. Keeping health and safety documentation is not an easy task and often raises many doubts. This is due to two things, namely:

- the lack of a specific form and scope of mandatory data that should be documented as part of a given issue

- the lack of direct legislative requirement for the issue

Due to the possibility of control, people responsible for occupational health and safety must often demonstrate that they fulfil the obligations arising from the entrusted function and document almost everything. This is a simple task in case of a small business with a negligible risk to employees. Challenges arise when a company consists of a large number of employees and, as a result, the work risk is greater.

The occupational health and safety management system is an element of the superior company management system, which consists of:

- organisational structure 
- planning

- responsibility

- rules of conduct

- procedures, processes and resources

The above elements are components necessary to develop, implement, review and maintain occupational health and safety policy, and thus to manage occupational risk in the work environment in connection with the work performed in individual departments and teams.

OHS management systems are all legal, technical and organisational measures, which are aimed at protecting people in the process of their work, against threats arising from the material work environment as well as against occupational diseases and accidents at work (B. Dołęga, 2008).

The OHS system, which aims to permanently strive for continuous improvement, should be based on the guidelines and requirements of Polish standards:

- PN-N-18001: 2004 "Occupational Health and Safety Management Systems. Requirements."

- PN-N-18004: 2000 "Occupational Health and Safety Management Systems. Guidelines."

\section{Method of research}

Desk research is a technique for obtaining information that already exists. In other words, it is an analysis of existing sources and documents. As the name suggests, the test is performed from behind the desk. Sources of available data are primarily the Central Statistical Office (GUS), statistical data, trade press, all information obtained from legal available sources.

Desk research is most often practiced at the beginning of the research to gain insight into the subject and obtain information necessary for further actions.

Reliable analysis of existing data is the basis for a well-conducted next part of the research process. Data analysis is also a selection of available information. Not everything that is available is valuable from the point of view of the subject of the study. The main purpose of carrying out desk research is to select information and give the right direction to further actions. In addition, thanks to the analysis of documents, the researcher is able to verify and specify knowledge on a given topic.

The reliability of the information obtained depends on two factors:

- availability of existing documents and appropriate selection of sources;

- proper data processing.

As a rule, the existing data analysis is an introduction to the comprehensive research process. However, there are situations where desk research is the main study. It is possible when the existing sources provide sufficient information and when the reliability of the research will be compared to other research results obtained using other techniques. In addition, when there are no other techniques to collect data in this research process. It may also be the researcher's decision to exclusively use existing data analysis for organisational, legal or economic reasons. Another technique used in the study is a survey. Researchers say that it is a form of an interview. However, it is different from an actual interview as regards three features: 1) the degree of standardisation of questions asked; 2) the scope and "depth" of the issue and 3) the principles of the study, and hence the distance that is minimised during the interview.

"Therefore, the survey is a technique of gathering information consisting in completing, usually by the respondents themselves, special questionnaires, mostly with a high degree of standardisation, in the presence of an interviewer or, more often, without the interviewer."(T. Pilch, 2001)

This is the most common tool for collecting information. Surveys are used to conduct research on a representative group for a given population, which results in the possibility of generalising them in relation to the entire population.

The following table presents the advantages and disadvantages of conducting research using the survey.

Table 1. Advantages and disadvantages of research conducted with the use of survey

\begin{tabular}{|c|c|}
\hline Advantages & Disadvantages \\
\hline $\begin{array}{l}\text { - } \quad \text { the research can cover a large population } \\
\text { - a survey can be anonymous, } \\
\text { which is an important information for } \\
\text { respondents }\end{array}$ & $\begin{array}{l}\text { - } \quad \text { no possibility to deepen the question } \\
\text { - } \quad \text { no possibility to further clarify the answer } \\
\text { - } \quad \text { no researcher's control over the answers } \\
\text { given (e.g. perfunctory statements) } \\
\text { - no personal contact with the respondent }\end{array}$ \\
\hline
\end{tabular}


- it does not generate relatively high costs of the research

- it makes it possible to reach a large number of people in a relatively short time

- compilation of results and analysis of studies is not problematic for researchers
- the need to adjust the language of the survey so that it is clear and understandable to each of the potential respondents

Source: own elaboration

The basic tool in surveys is a questionnaire. In the introduction, the researcher should explain the purpose of the study, its aim and subject. It is also necessary to include a brief instruction on how to complete the questionnaire. This makes it easier for respondents to give answers as well as for the researcher to compile data.

At the stage of constructing the questionnaire, the researcher must ensure that the questions in the questionnaire are logically ordered. Their order is very important. General questions should be asked first, and then the more specific ones. It is also important to organise the questions thematically in case the survey is multithreaded.

Depending on the researcher's decision, a metric should be placed at the beginning or end of the study. It should include, for example, questions about age (in ranges), size of the place of residence, education, occupation and other, if required for the study.

The most commonly used types of surveys are:

- postal survey - consisting in sending questionnaires to respondents via traditional mail, together with an instruction attached

- $\quad$ online survey - delivery of survey questionnaires takes place e.g. via e-mail or by posting questions on the website

- auditorium survey - completed "in the room"/"in the auditorium," in which the participants of the study are gathered.

The survey was conducted among employees of the Research and Innovation Centre Pro-Akademia. The anonymous survey consisted of questions regarding the OHS system and compliance with its principles, as well as OHS training. The vast majority of respondents are employees with 3-4 years' experience. This indicates that the Research and Innovation Centre Pro-Akademia team is young and is made up of scientists involved in research and development projects.

\section{Research results}

\section{What should an OSH management system look like in a company?}

Management can be understood as the planned and organized impact of the management system on the managed system, which includes everything that leads directly to meeting the requirements. The indicated approach to the management process can also be referred to the area and specifics of occupational health and safety 45020: 2009., 2009). The basic requirements for the OHS management system in a company arise from the provisions of law, according to which it is the duty of each employer to carry out occupational risk assessment and to use the resulting protection measures, as well as to train and inform employees about hazards at the workplace. The effective implementation of these and other legal requirements may be facilitated by the implementation of the OHS management system, the model and elements of which are described in the Polish standard PN-N-18001: 1999 "Occupational health and safety management systems. Requirements." The OHS management system presented in this standard consists of:

- management commitment and occupational health and safety policy

- planning

- implementation and functioning

- monitoring, auditing and corrective actions

- review carried out by the management and continuous improvement of the OHS management system. 


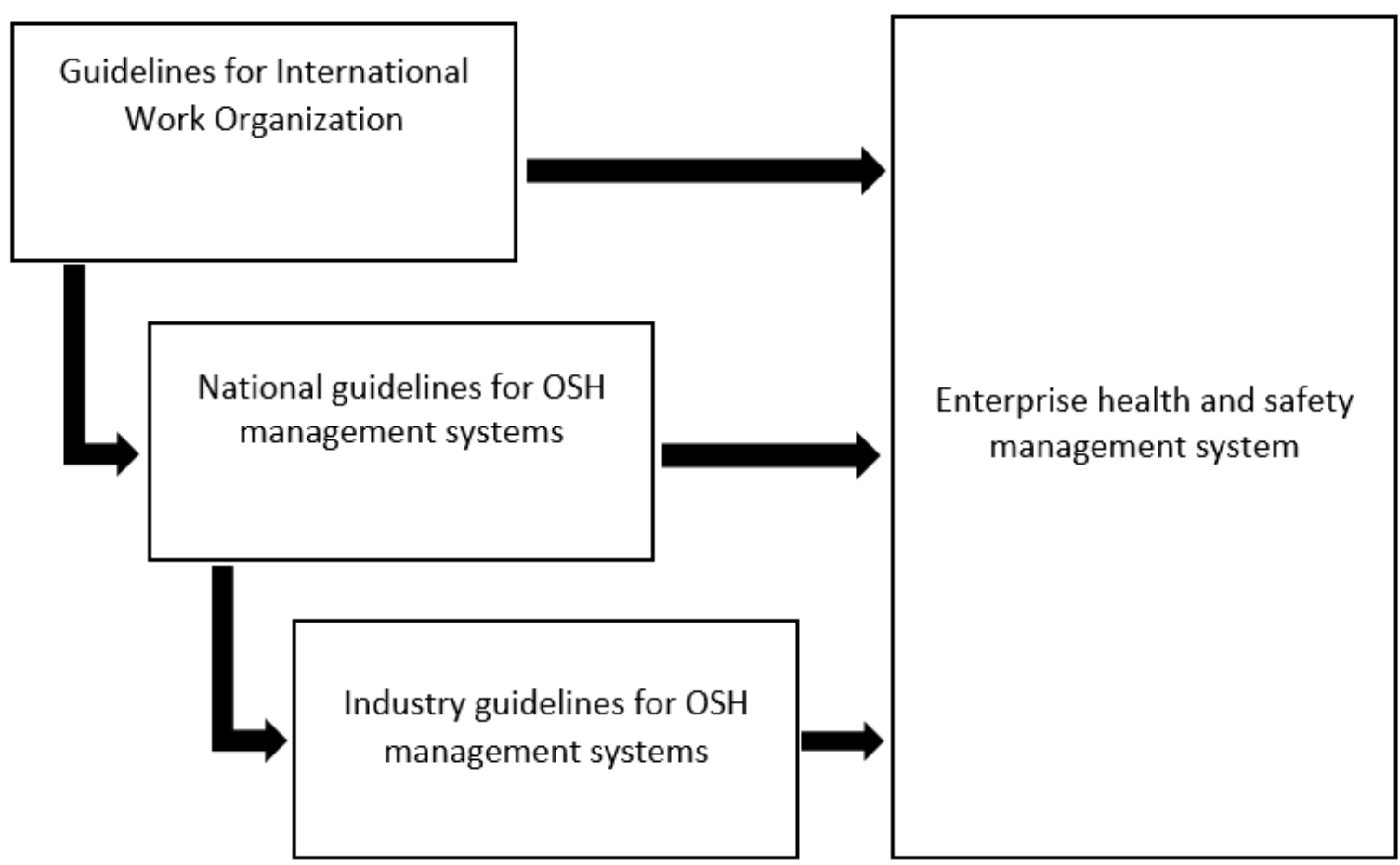

Figure 1. Elements of occupational health and safety management system structures Source: International Labour Organization (ILO) guidelines

The main emphasis in the management system should be put on the process of permanent improvement of both the company and the management system, and thus security policies. Deming cycle (also referred to as PDCA cycle: Plan-Do-Check-Act, or PDSA cycle: Plan-Do-Study-Act) - a diagram illustrating the basic principle of continuous refinement (continuous improvement, Kaizen), created by William Edwards Deming, an American specialist in statistics working in $\underline{\text { Japan. }}$.

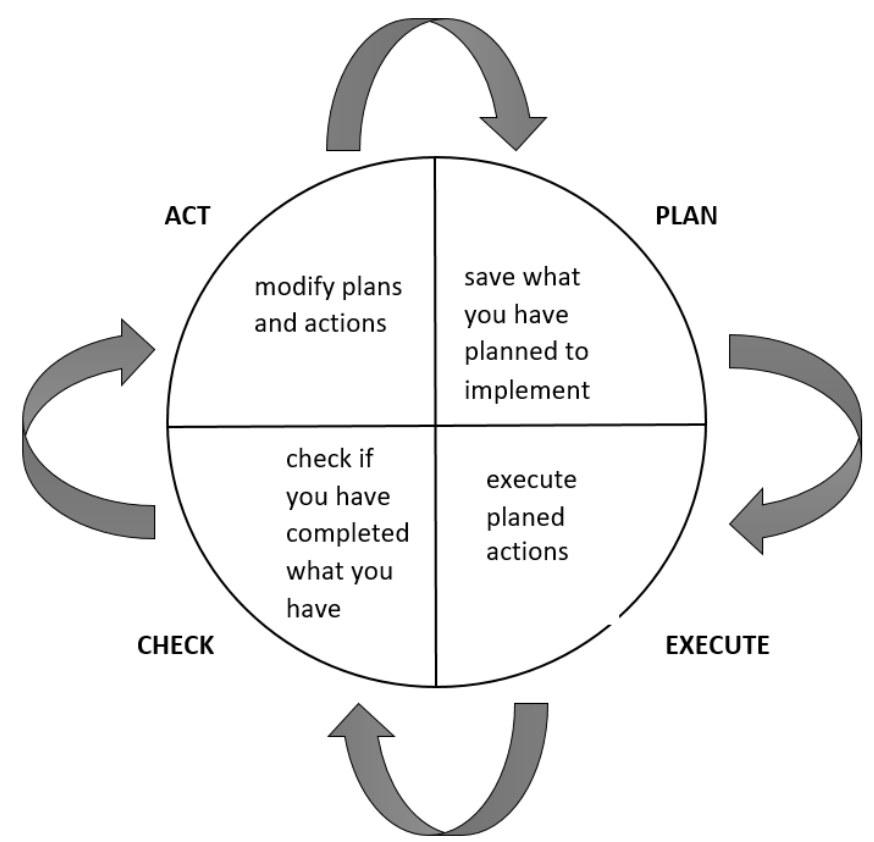

Figure 2. Deming Cycle

Source: Cf. i.a. A. Hamrol, Zarzqdzanie jakościq z przykładami [eng. Quality management with examples], PWN, Warsaw 2005, p. 156 
The system approach implemented in occupational health and safety management seems to be perfect. The implementation of system solutions makes it possible to implement security development processes similar to the neighbouring areas of company management (quality, environment, information, finance, etc.). The use of a system approach in managing work safety is associated with the fact that many characteristic management issues (areas) should be taken into account. One of them is the area of shaping pro-humanistic requirements, making it possible to adapt the existing working conditions to the needs and expectations of the interested people. Their inclusion in the management process makes it possible to increase the efficiency of the work performed and minimise the adverse burdens associated with professional tasks (A. Górny, 2015).

The application of the system approach in shaping work safety requires covering all areas of the company's operations with the conducted activities. These areas can be identified as:

- management commitment in development of occupational health and safety policy, taking into account the participation of employees in undertaking system activities

- planning the implementation of appropriate actions

- identification of legal and normative requirements

- defining general and specific goals and planning their implementation

- defining the structure, responsibility and authority relevant to functioning of the system

- providing necessary resources, including competent and responsible employees

- defining the rules of communication

- development of system documentation, along with identification of rules of supervision over documents and records conducting occupational risk assessment and options of performing work

- proper planning and organization of works associated with significant risks

- ensuring the possibility of operational control related to readiness to take appropriate responses to accidents at work and serious failures

- development of purchasing processes, taking into account aspects of security of goods and services purchased

- checking the functioning of the system and testing its compliance with the law,

- indication of non-compliance, together with taking corrective and preventive actions (Dahlke, 2000).

\section{Results of the research}

\section{Human factor in occupational health and safety management}

There is no doubt that the human factor is the most important link in the entire occupational health and safety management chain.

It is the very core of the management system. These are people that are the basic unit determining the effectiveness of implemented tasks. Due to the above, the nature and scope of tasks assigned to employees should be treated as extremely important. From a system perspective, an additional aspect to which attention should be paid is whether the possibility of performing an action resulting from the implementation and functioning of the system has been provided (A. Górny, 2015).

Taking action can be equated with managing people. Ensuring the efficiency of performing system tasks requires:

- Determining the competences of persons performing activities affecting occupational health and safety,

- Ensuring the implementation of trainings and instructors, thanks to which employees acquire knowledge and skills necessary to perform the scope of duties,

- Taking care of ensuring staff awareness regarding the implementation of tasks,

- Possession of records confirming education, training, skills acquired and staff experience (Karczewski T., 2009).

The state of occupational health and safety can be treated as one of the basic indicators of assessing satisfaction that affects the level of satisfaction with the work environment (A. Górny, 2015). 


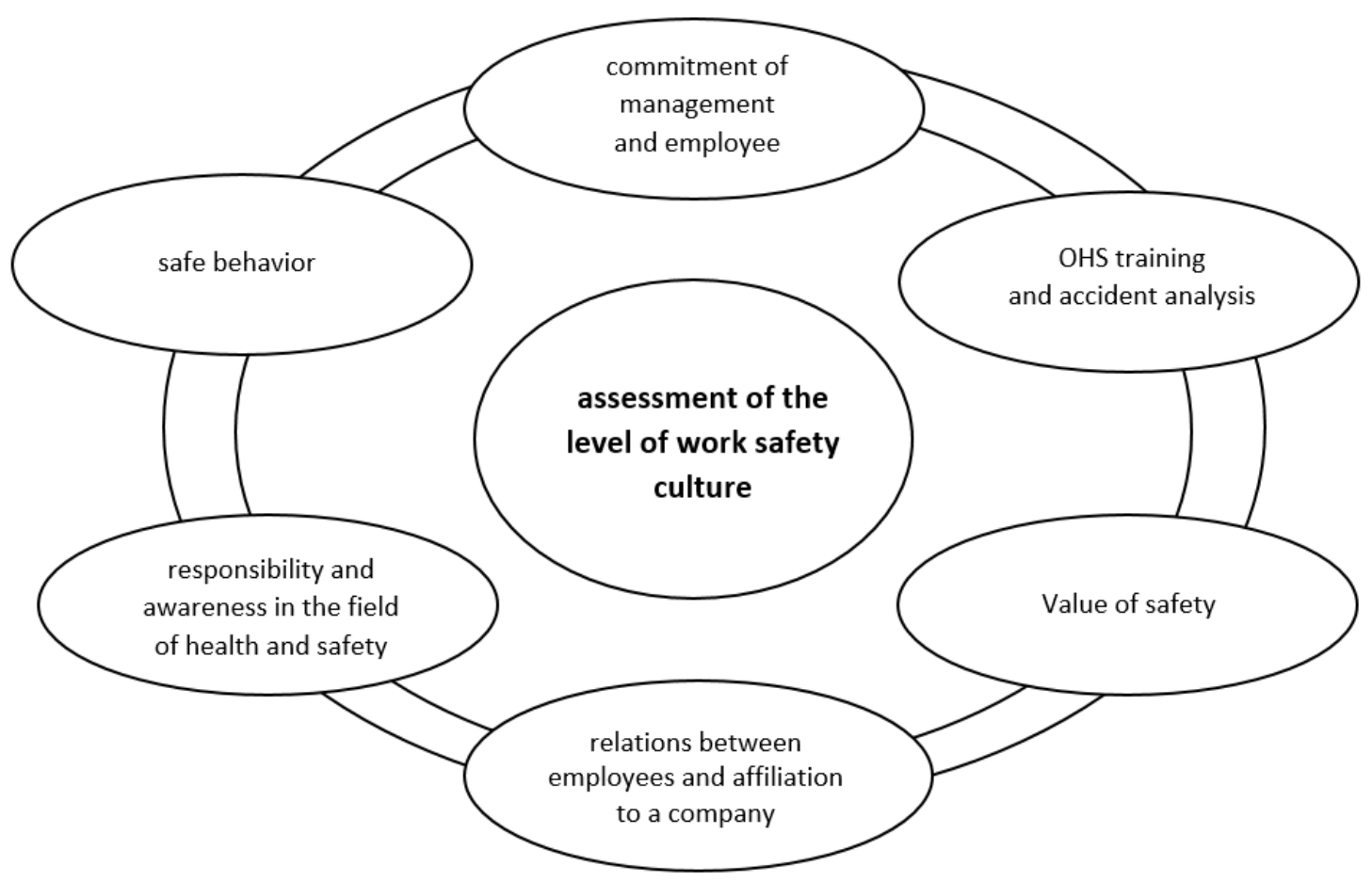

Figure 3. Company security culture - aspects of evaluation Source: Milczarek, 2002

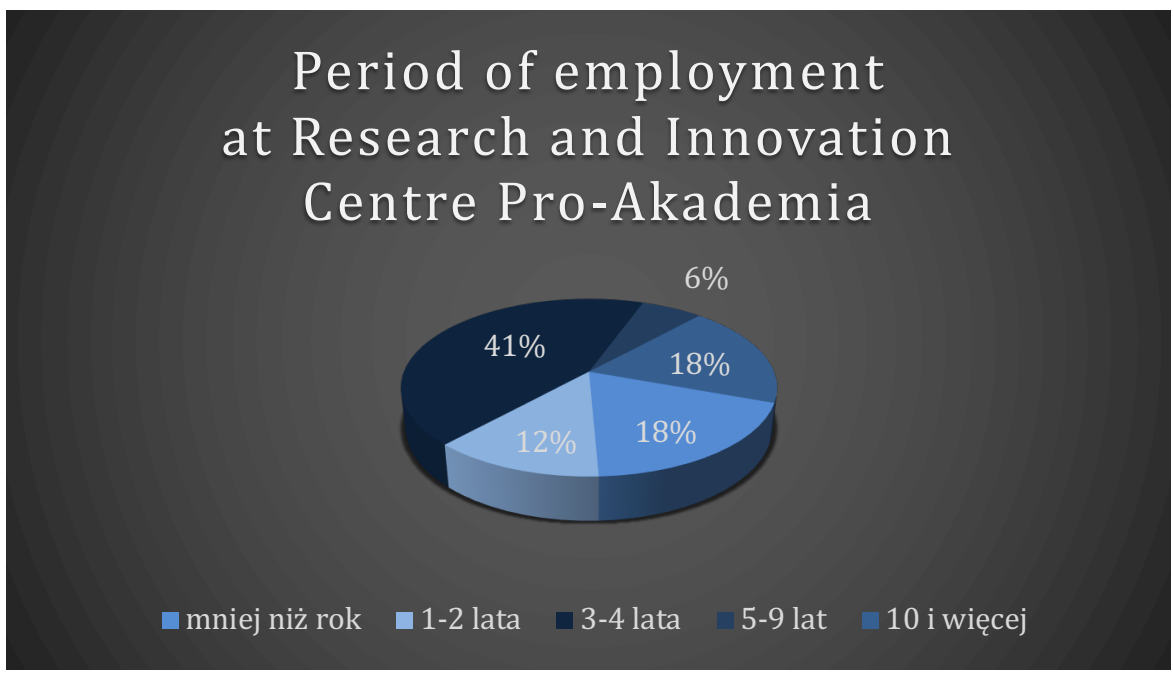

Chart 1. Period of employment at Research and Innovation Centre Pro-Akademia Source: own elaboration based on a survey 


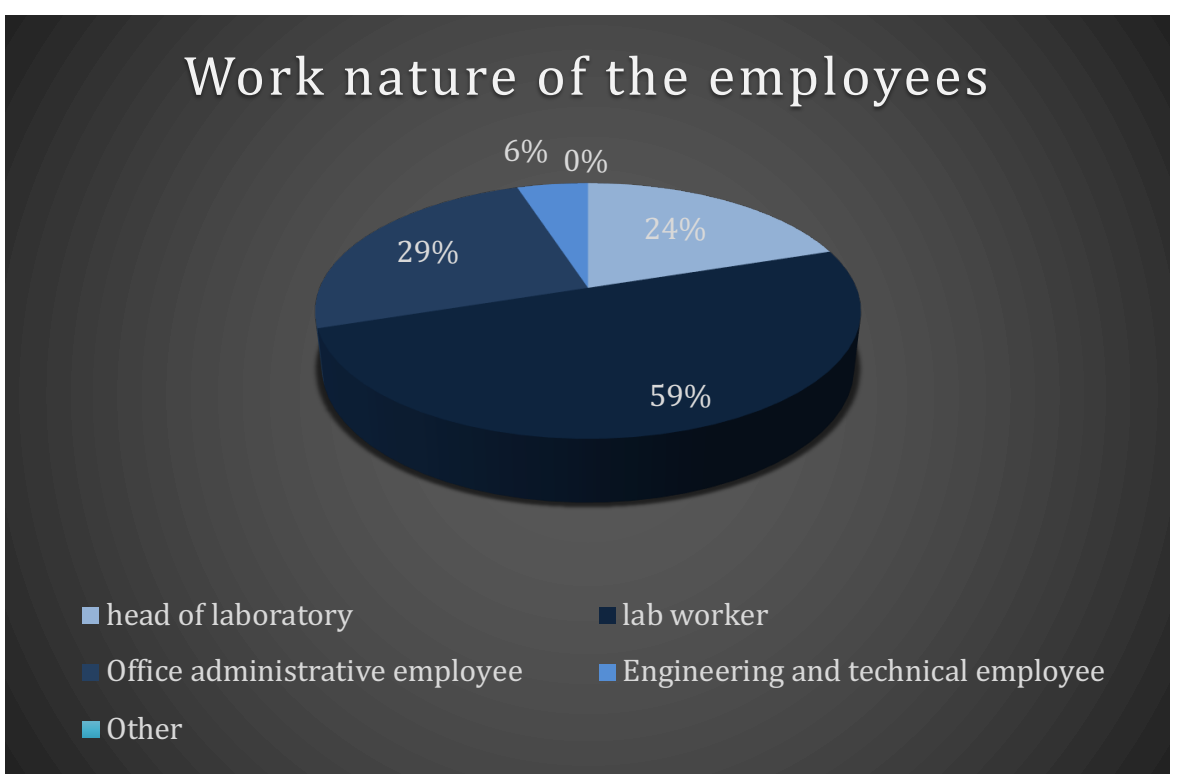

Chart 1. Work nature of the employees

Source: own elaboration based on a survey

Based on the survey, it was found that $35 \%$ of respondents admitted to working without the recommended collective or personal protective equipment. The most frequently mentioned reasons why this happens include: rush, overconfidence, lack of awareness of the threat.

Actions that should be taken to minimise the phenomenon of work without personal protective equipment are the increased attention of laboratory managers and the person responsible for occupational health and safety. Increased inspections in the laboratory work rooms and trainings reminding about the effects of the lack of personal protective equipment.

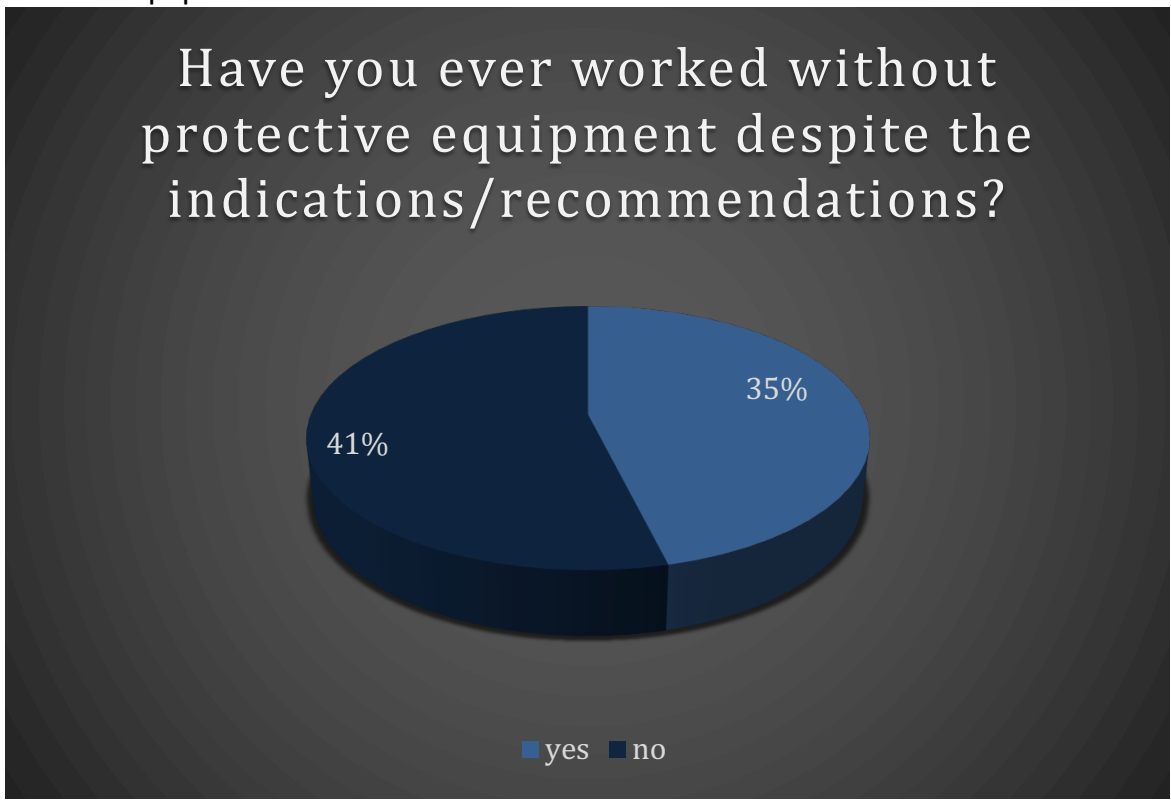

Chart 2. Work without protective equipment

Source: own elaboration based on a survey

Respondents assessed the usefulness of OHS training as useful on a five-point scale (1 - least useful, 5 - very useful). $47 \%$ of them marked the answer 5 and $29 \%$ - answer 4.

It was found that for almost half of the employees training is useful. However, it is worth noting that OSH training is not an unpleasant obligation for both the instructor and the new employee. OSH training is the first duty, the first task to perform and also the first contact with other employees. In view of the above, every effort should be made to ensure that the training is a source of information provided to employees in the most possible attractive form. 


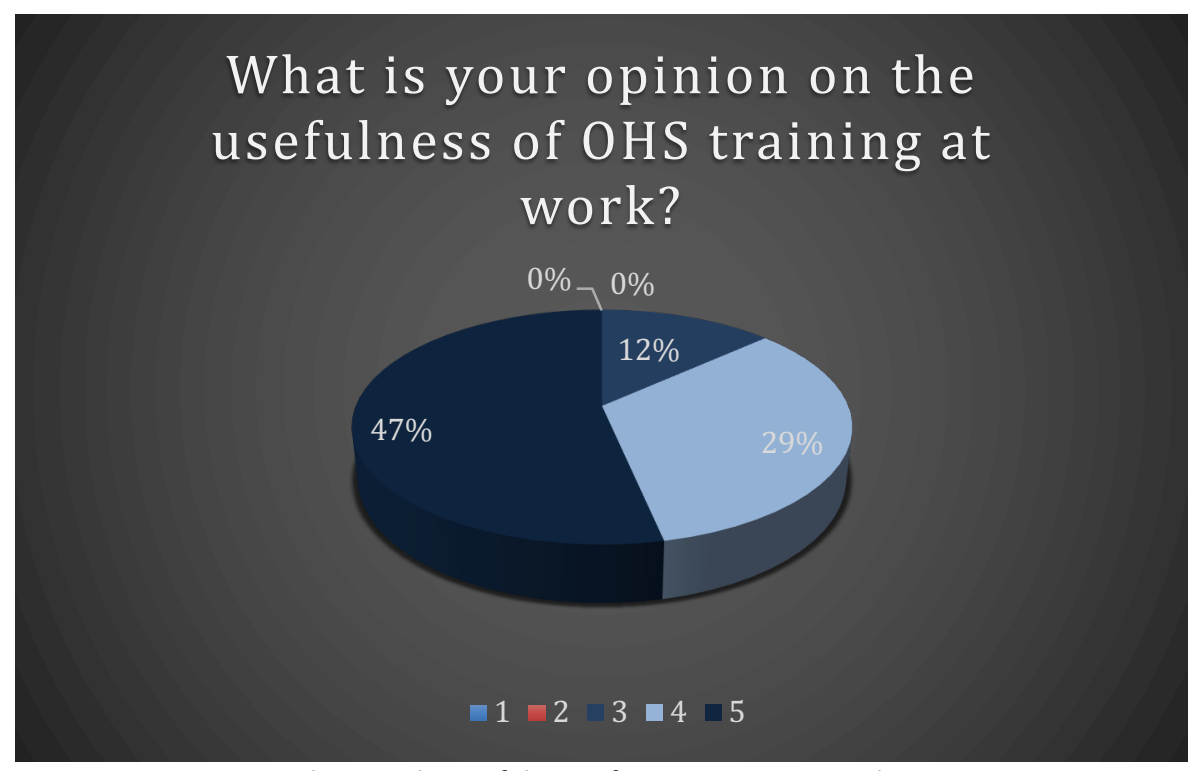

Chart 3. The usefulness of OHS training at work

Source: own elaboration based on a survey

Almost half of the employees of the Research and Innovation Centre Pro-Akademia assess their knowledge of OSH as very good. $29 \%$ of respondents selected level 3 on a five-point scale.

Such data forces us to analyse methods and techniques that are currently used in OHS training for people working in laboratories. One needs to choose the right content and the way it is transmitted. Changes in the initial and periodic training will allow more employees to become aware (both those who have some knowledge in this field after the initial training and those who will take it for the first time).

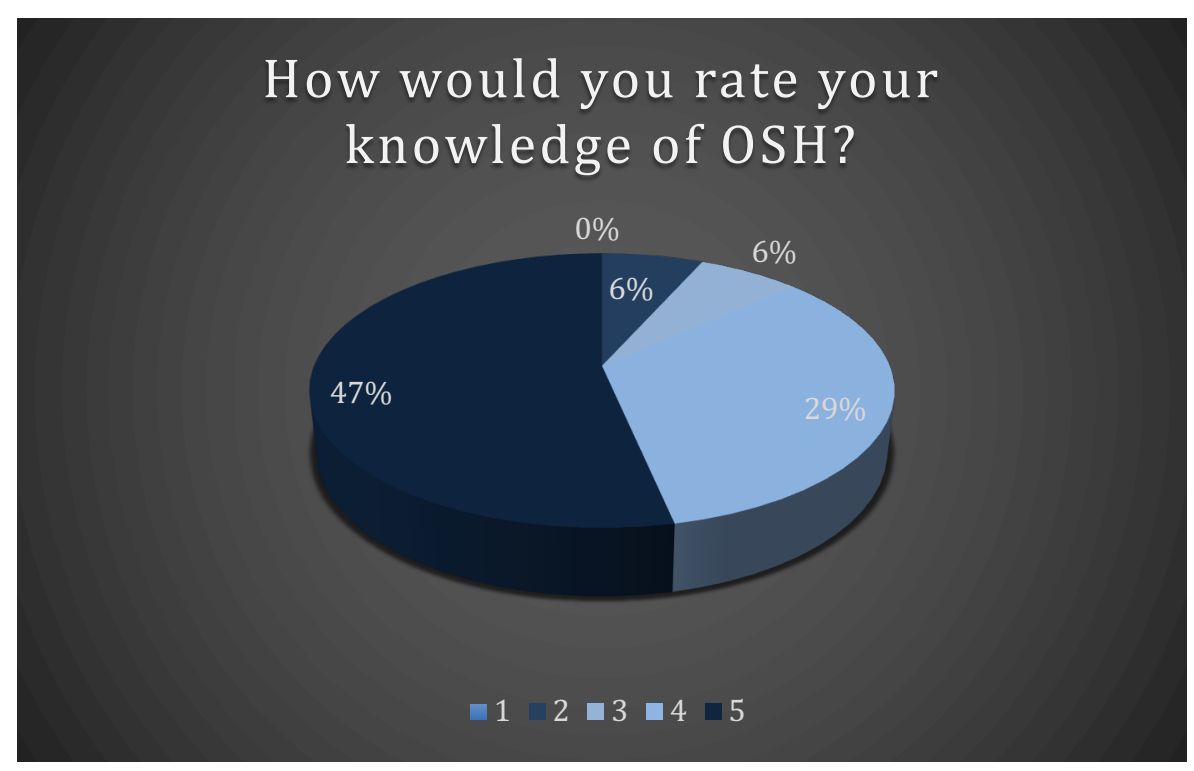

Chart 4. Knowledge of OSH

Source: own elaboration based on a survey

The most frequently mentioned reasons for disregarding OSH regulations include: routine and lack of awareness of the threat. The intentional non-compliance, overconfidence and stress answers were indicated by $24 \%, 29 \%$ and $35 \%$ of respondents respectively. 


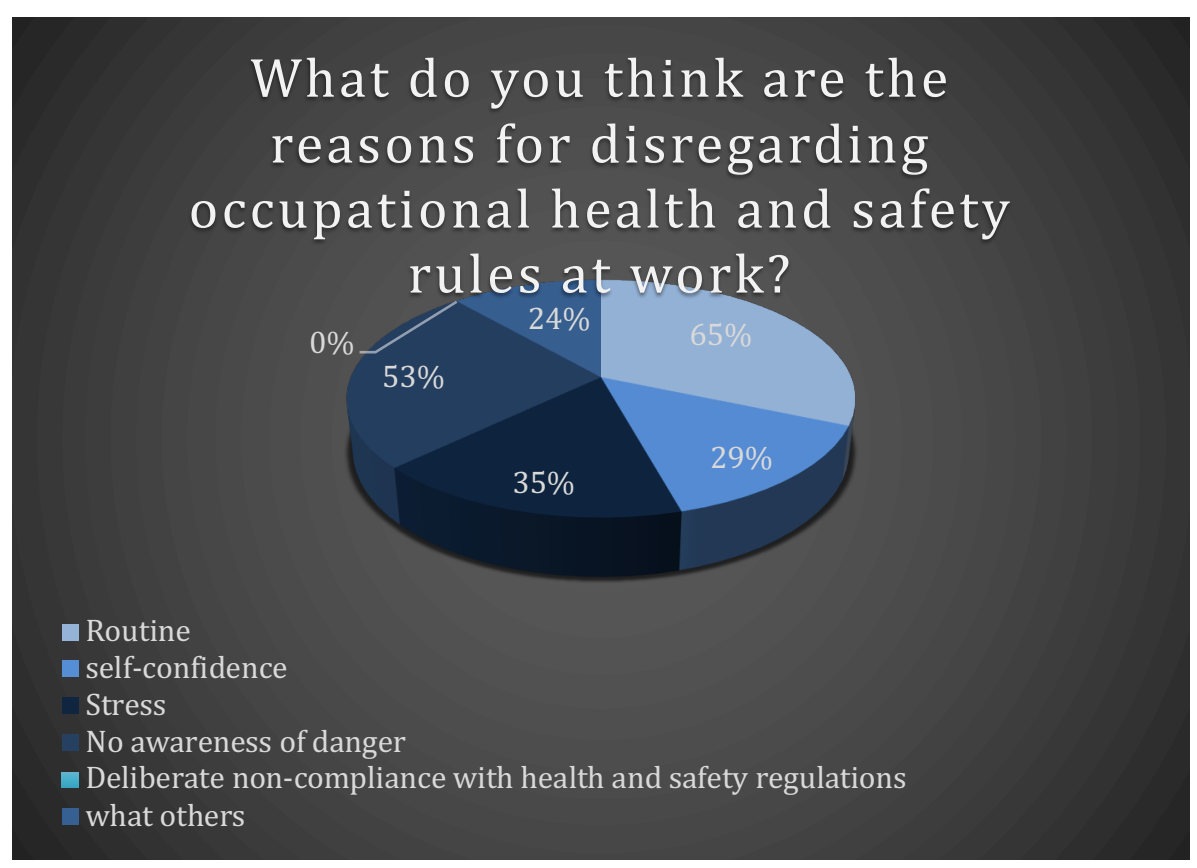

Chart 5. Reasons for disregarding OSH rules Source: own elaboration based on a survey

According to $82 \%$ of respondents, the knowledge provided during OHS training is sufficient to be able to work safely.

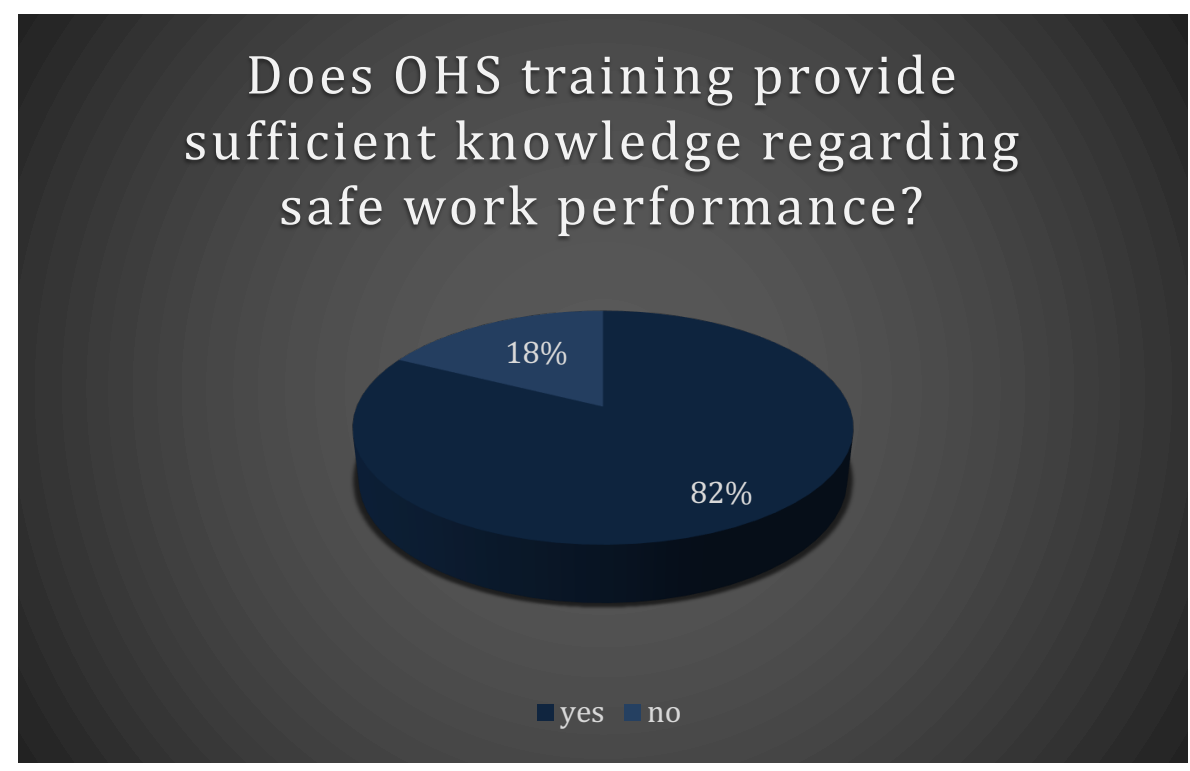

Chart 6. The usefulness of OHS training

Source: own elaboration based on a survey

OHS procedures are clear and transparent for every employee. Employee self-assessment in terms of understanding $\mathrm{OHS}$ procedures is very high. However, the question should be asked whether this translates into the way the duties are performed. The answers given to the above questions lead to the question of whether or not every procedure is clear. The OHS system is constructed primarily for the needs of employees, so that they can refer to it at any time and adhere to the rule while performing their duties. At the time of change, it is a ready collection of documents, based on which we are able to update and improve what was not perfect in the past. 


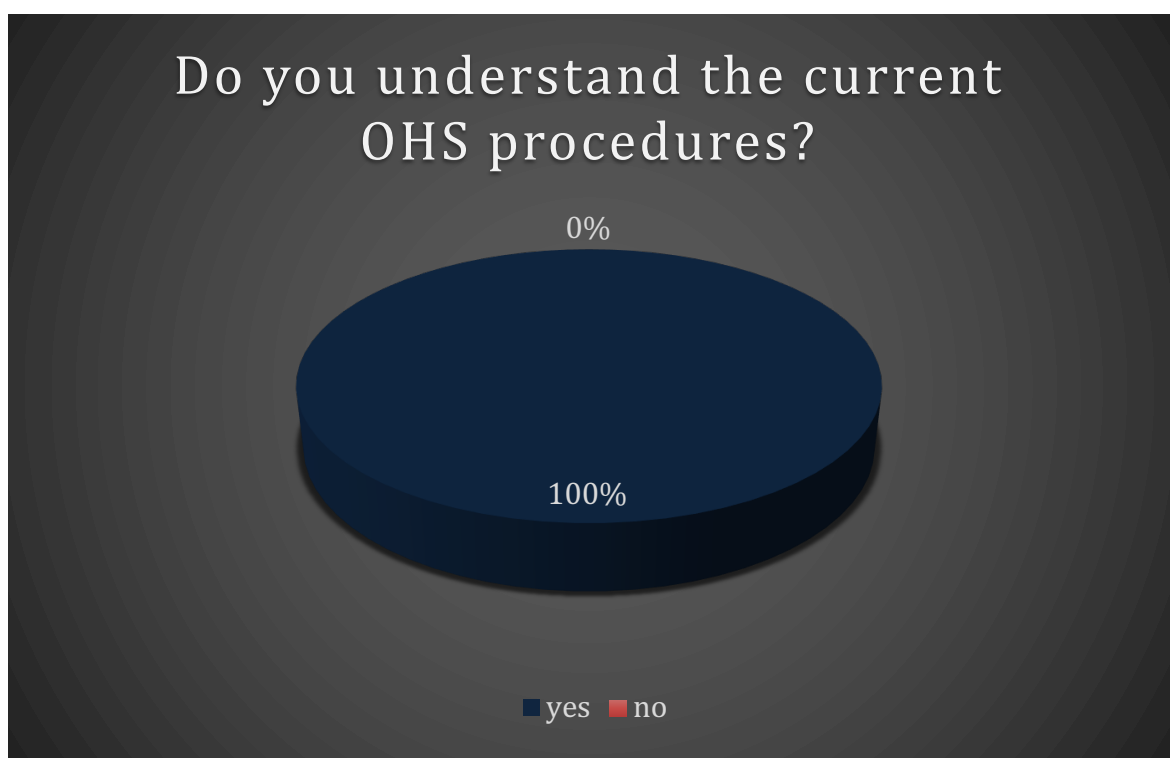

Chart 7. Transparency of $\mathrm{OSH}$ rules

Source: own elaboration based on a survey

According to $24 \%$ of respondents, OHS procedures are an element that hinders the daily performance of duties. This assessment of the situation may result from the lack of knowledge about the necessary safeguards. A situation when the rush will decide what actions employees will manage to perform and which ones they will skip cannot occur. The employer's task is to make people aware of the threat and the importance of the need to follow procedures. Internal regulations are built by the team, so if a given procedure does not apply in practice, then the issue should be discussed in a larger group of people and the necessary corrections to the system should be made.

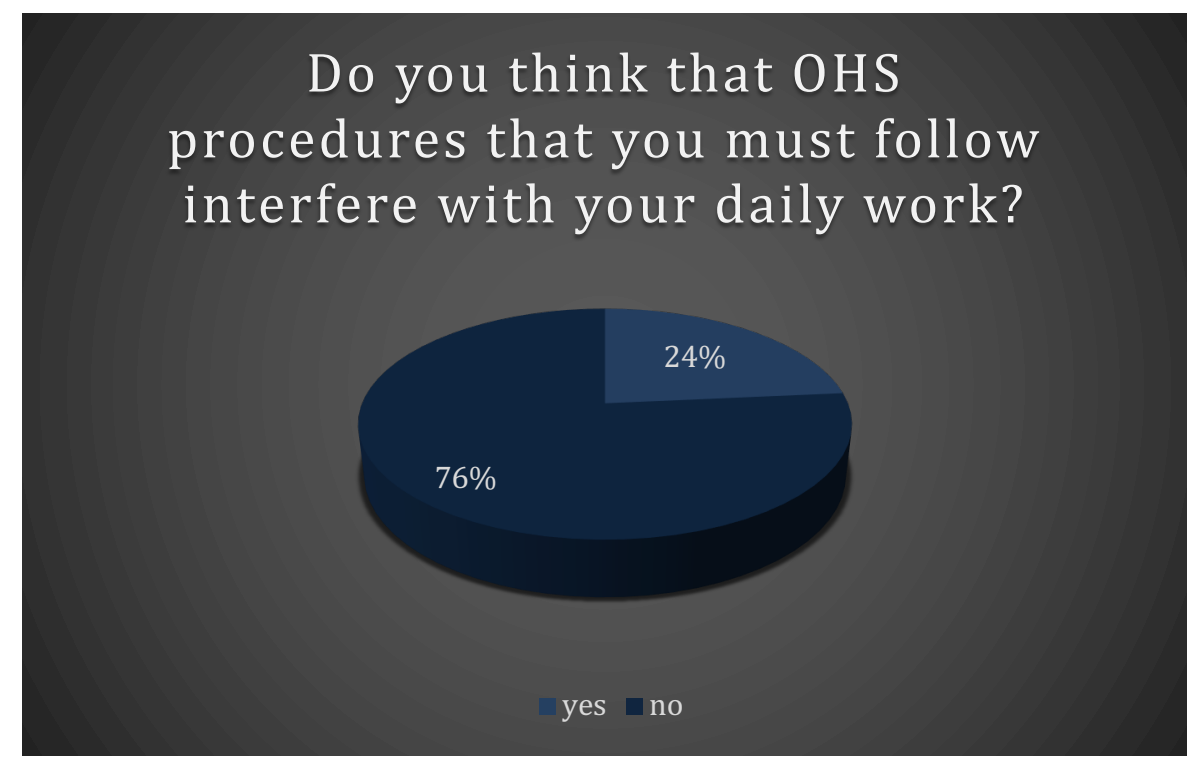

Chart 8. OHS procedures as a hindrance to everyday work Source: own elaboration based on a survey

On the other hand, according to $12 \%$ of respondents, not all procedures are needed at the workplace. 


\section{Are all OSH procedures in your \\ workplace necessary?}

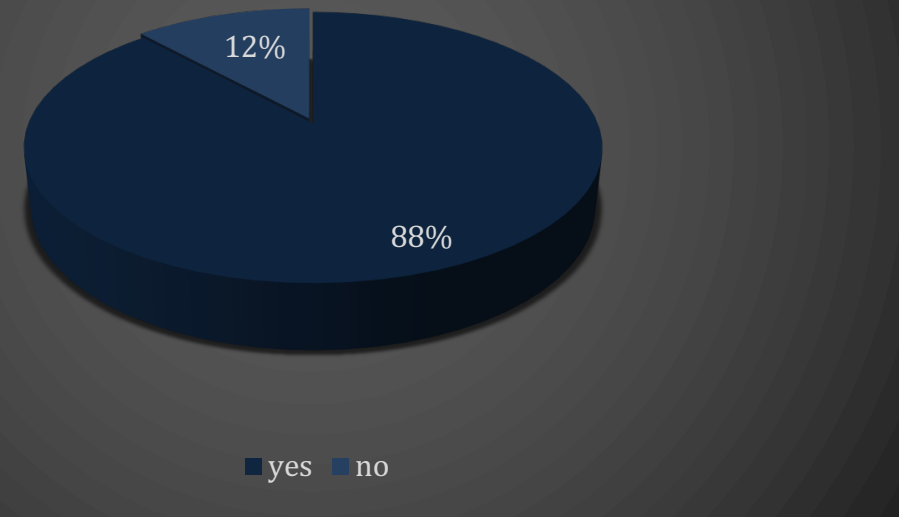

Chart 9. Usefulness of OHS procedures

Source: own elaboration based on a survey

All employees participating in the survey declare that they know the procedure to be followed in an emergency or accident. It is very difficult to predict how people will behave in an emergency situation under stress, worrying about their and their colleagues' life and health. In view of the above, it should be remembered that knowledge of the theory is the indispensable minimum to be able to assess situations and react appropriately in an emergency. The employer, making every effort to ensure that responses in emergency situations are appropriate, should ensure the appropriate frequency of refresher training in first aid.

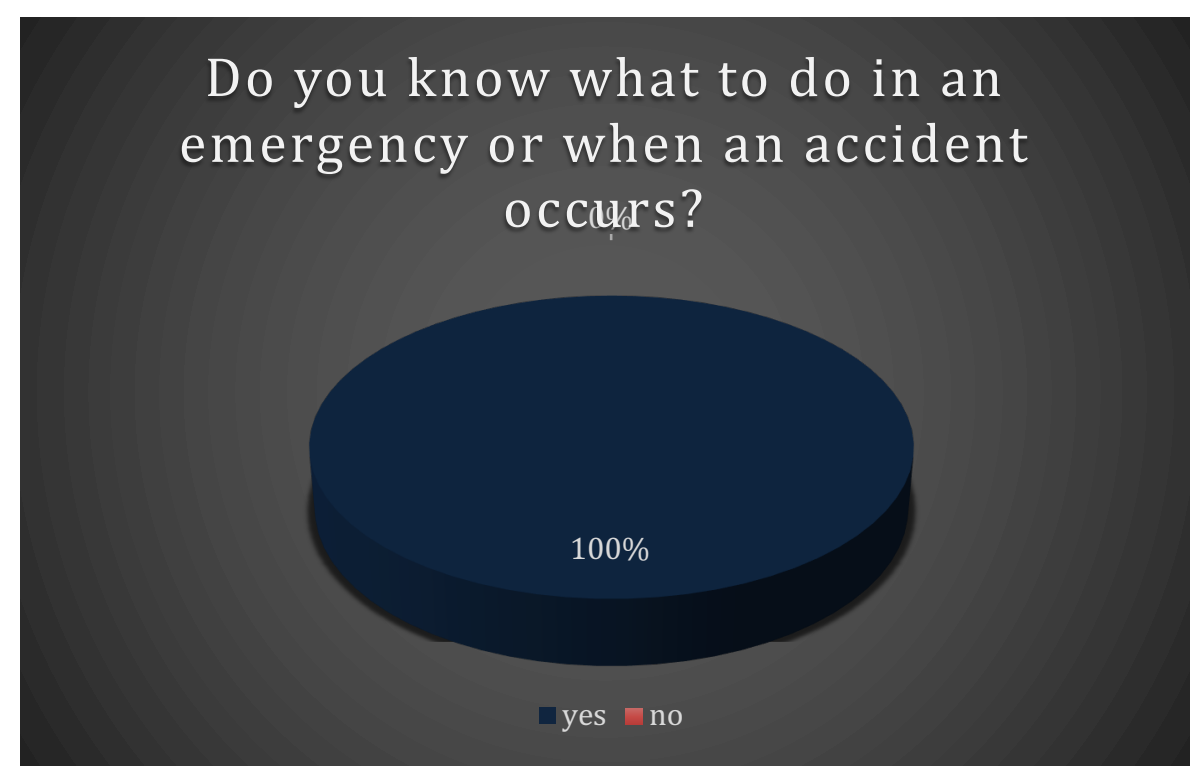

Chart 10. Response to an emergency or accident Source: own elaboration based on a survey

\section{Discussion with the other scientists and papers}

The occupational health and safety system is part of a broader company management system. The research shows that the employees of the Research and Innovation Centre Pro-Akademia are aware of how standards and regulations work. They are familiar with OHS rules and know what behaviours are appropriate in an emergency. Unfortunately, despite understanding the legitimacy of the regulations, they believe that there are such rules that interfere with everyday work or are unnecessary at all. The approach to OHS training also needs to be 
considered because, despite employees' declarations that the training is a sufficient source of knowledge, there are cases of non-compliance with occupational health and safety regulations. The answers to the question of what this results from were spread out among all the options. The reasons for non-compliance with OHS regulations are: routine, overconfidence, stress, lack of awareness of the danger and/or the intentional disregard of regulations.

The issue of participation is especially important in the context of the integration of Poland with the European Union and the implementation of its directives. One of them is Framework Directive 89/391/EEC, in which cooperation and employee involvement in activities related to ensuring safety and health protection at work are emphasised. The system should be based on co-decision and consultation training. A system approach to OHS issues in a company is presented in the book OHS Management System. A Tool for Continual Improvement very carefully. According to Frick K, the OHS management system cannot be treated as a panacea for ensuring a stable and sustainable work environment. The implemented systems have their strengths and weaknesses, while the effectiveness depends on how the system is understood and implemented in the company. According to OHS Management System. A Tool For Continual Improvement, excessive document production is a weakness. The amount and legitimacy of documentation should be controlled because it can make us forget about the most important thing, which are people, and focus on the production of documentation instead. (Frick K., Jesen PL, Quilian M, 2000)

Although OHS management systems are currently being implemented by companies around the world, there is still no universally agreed consensus in the field of OHS management, as emphasised by Nielsen (European Agency for Safety and Health at Work EU-OSHA, 2010).

OHS management systems are obviously not a well-defined set of management systems. There are no clear boundaries between OSH activities, OSH management and OSH management systems. A "system" consists of many parts or components connected together that interact in an organised way (K. Nilsen, 2000).

According to one definition, the OHS management system is "a set of related or interacting elements for determining the principles and objectives of OHS and achieving those goals. These elements may include OHS policy, planning, organisational structure and accountability, communication and training, risk management, monitoring as well as corrective and preventive actions. Continuous improvement is one of the most important elements of successful system operation and is closely related to performance assessment and is based on the well-known Plan-Do-Check-Act (PDCA) model, also known as the Deming cycle. (WE. Deming, 1982)

The study shows that, despite many areas that have been well assessed, the works on improving the conditions and management of the OHS system at Research and Innovation Centre Pro-Akademia should not be stopped. A great example are the answers to the question about the reasons for non-compliance with OHS regulations, where routine was mentioned quite often. As Nils K. states, one must not forget about the human, the essence of the organisation, as well as the participatory approach of each participant in the management process, regardless of their position level.

The perfect conclusion seems to be the need to remember about the Deming cycle, the essence of which is continuous: planning - write down what you should do; doing - do what you planned; checking - check if you did what you planned; and acting - modify plans and actions.

\section{Uncertainty and impact of research results on science, economy, environment and society}

Living in a world of norms and regulations, we are forced to organize work spaces in a certain way. It should be remembered that following the letter of the law and introducing standards for the daily performance of duties is intended to guarantee safety in everyday life. The approach to standards should be based on the belief that they are intended to secure opportunities, and not limit them.

Lack of detail as to how the OHS documents should be created should be seen as an opportunity to build one's own company management system. The general scope described in the legislation and standards is the basis for developing one's own occupational health and safety management system. Obligations related to OHS service documentation are a very broad topic. The manner of fulfilling the obligation related to keeping documentation has been signalled by stating that it is necessary to keep records, complete and store documents regarding the working conditions for an appropriate period, identify occupational diseases and suspicions of such diseases, store test results and measure factors harmful to health in the work environment. The field for self-organisation of the OHS system allows the inclusion of all participants to create internal rules and procedures. As a result of discussions with each employee, there is a chance to create internal rules understandable for each system participant. Most importantly, each employee then becomes the author of the regulations, not just their 
follower. This translates directly into the ability to move among regulations and procedures as well as their understanding and legitimacy. The implementation of an OHS management system in a company may not only facilitate compliance with applicable law, but also enable the achievement of measurable benefits related to the improvement of OHS level. An effective OHS management system makes it possible to:

- reduce the number of accidents at work, occupational diseases and related losses

- reduce absence of employees caused by sickness

- increase productivity and improve the quality of work.

Both OHS status and actions taken to improve it should be monitored. Proactive monitoring, including checking the degree of implementation and effectiveness of plans, procedures, as well as preventive and protective measures against accidents at work and occupational diseases, is of basic importance in the OHS management system. It should lead to the detection of threats and the use of appropriate preventive measures to prevent such events. Analysing the causes of accidents at work, including non-traumatic accidents and occupational diseases, are elements of reactive monitoring, which may indicate deficiencies and shortcomings in the occupational risk assessment and the use of preventive measures.

\section{Summary and conclusions}

Global trends and willingness to prove oneself against the background of not only domestic competition, but also European and global one, are conducive to designing and implementation of occupational health and safety management systems in a company.

Contemporary organisations operating in dynamically changing conditions are forced to find solutions improving individual areas of operation. What is more, efforts are being made to integrate activities in various areas contributing to increasing their efficiency and reducing own costs. The benefits of implementing an occupational health and safety management system are as follows:

- organization of formal and legal status - compliance or greater probability of compliance with legal requirements

- easier compliance with work safety requirements

- quick detecting and removing any potential non-conformities by preventing, and not correcting them

- raising team awareness about the essence of OSH

- reducing the number of accidents by supervising potentially accidental events and introducing preventive actions based on them

- a smaller number of employees exposed to harmful factors after identifying threats and taking appropriate actions (a smaller number of employees affected by occupational diseases)

- reducing the level of occupational risk

- building the company's image as socially responsible

- increasing the company's credibility

- improving the company's image

- confirmation of the importance of occupational health and safety in the company's activities

- meeting customer expectations

- improving relations with working conditions supervision bodies.

\section{References}

[1] A. Górny, Humanistyczne aspekty zarządzania bezpieczeństwem pracy. [Eng. Humanistic aspects of occupational safety management.] (39), 2015

[2] B. Dołęga, Praktyczny poradnik dla służb BHP. [Eng. A practical guide for OHS services.], 2008

[3] Dahlke, G., Zarządzanie bezpieczeństwem pracy i higieną pracy. Modele systemowego zarządzana bezpieczeństwem i higieną pracy. [Eng. Occupational health and safety management. Models of system management of occupational health and safety.], 2000

[4] European Agency for Safety and Health at Work EU-OSHA. (2010). Mainstreaming OSH into business management. In Working Environment Information. https://doi.org/10.2802/2138

[5] Frick K., Jesen PL, Quilian M, W. T., Systematic Occupational Health and Safety Management Perspectives on an International Development, 2000

[6] K. Nilsen., Systematic Occupational Health and Safety Management. Perspectives on an International Development, 2000

[7] Karczewski T., K. K., Zarządzanie bezpieczeństwem pracy. [Eng. Work safety management.], 2009

https://doi.org/10.32933/Actalnnovations.33.4 •ISSN 2300-5599 • C 2019 RIC Pro-Akademia - CC BY 
[8] T. Pilch, T. B., Zasady badań pedagogicznych. [Eng. Principles of pedagogical research.], 2001

[9] WE. Deming., Quality, Productivity, and Competitive Position,1982 